\title{
Thyroid function, morphology and autoimmunity in young patients with insulin-dependent diabetes mellitus
}

\author{
D Hansen, F N Bennedbæk ${ }^{1}$, L K Hansen, M Høier-Madsen² ${ }^{2}$ B B Jacobsen and L Hegedüs ${ }^{1}$ \\ Department of Paediatrics and ${ }^{1}$ Department of Endocrinology, Odense University Hospital, Odense, Denmark and ${ }^{2}$ Department of Autoimmunology, \\ State Serum Institute, Copenhagen, Denmark \\ (Correspondence should be addressed to D Hansen, Department of Paediatrics, Odense University Hospital, Sdr. Boulevard 29, DK-5000 Odense C, Denmark)
}

\begin{abstract}
Objective: An association between insulin-dependent diabetes mellitus (IDDM) and autoimmune thyroid disease is well recognized. We have studied the prevalence of thyroid dysfunction, autoimmunity and morphological abnormalities by ultrasonography in young diabetics.

Subjects and methods: Among young IDDM patients less than 18 years old and living in the county of Funen, Denmark, 105 of 116 eligible patients participated. They were compared with 105 healthy children matched for sex and age. Routine thyroid function parameters (thyroxine $\left(\mathrm{T}_{4}\right)$, tri-iodothyronine $\left(\mathrm{T}_{3}\right), \mathrm{T}_{3}$ resin uptake and TSH) and thyroid autoantibodies (anti-thyroid peroxidase, TPOab, and thyroglobulin antibodies, Tgab) were measured. Thyroid size and morphology were determined by ultrasonography.

Results: Two of the diabetics had previously diagnosed hypothyroidism and three new cases of subclinical hypothyroidism were found. There were no significant differences in thyroid function variables or thyroid volume between diabetics and controls. Thyroid volume correlated significantly with age and weight in both groups. Among diabetics, 17 had thyroid autoantibodies (13 with TPOab, 14 with Tgab and 10 with both) compared with 2 children in the control group $(P<0.001)$. Forty-four with IDDM as opposed to 11 of the controls $(P<0.001)$ had morphological abnormalities at ultrasonography. Most of them had various degrees of hypoechogenicity thought to be a marker of thyroid autoimmunity. Among the 17 diabetics with autoantibodies, 10 had morphological abnormalities at ultrasonography.

Conclusions: A high proportion of young IDDM patients without any clinical signs of thyroid disease have markers of thyroid autoimmunity. Many have thyroid autoantibodies, but even more have abnormalities by thyroid ultrasonography.
\end{abstract}

European Journal of Endocrinology 140 512-518

\section{Introduction}

The association between insulin-dependent diabetes mellitus (IDDM) and autoimmune thyroid disease has long been recognized (1). In several studies of both children and adults with IDDM a high prevalence of thyroid autoantibodies (Tab) $(8-44 \%)$ has been found as an indicator of thyroid autoimmune disease (1-7). Most of those antibody-positive diabetics were clinically and biochemically euthyroid. How many of them will later develop thyroid dysfunction is uncertain. The Tab detected in previous studies have primarily been against thyroglobulin (Tgab) and microsomal antigens (Micab). It is now possible to measure the more sensitive and antigen-specific anti-thyroid peroxidase antibodies (TPOab) $(8,9)$. However, Tab in serum do not always appear in autoimmune thyroid diseases (10). There is a need for alternative ways to confirm the diagnosis of autoimmune thyroid disease. During the last decade thyroid ultrasonography (US) has been increasingly accepted as an easy, inexpensive and non-invasive method for the investigation of thyroid volume (11-13), morphology and echogenicity (14-17). However, in childhood diabetes little is known of thyroid morphology determined by US $(5,18)$.

In the present study we determined the prevalence of thyroid dysfunction, Tab and thyroid US abnormalities in an epidemiologically well-defined group of young diabetics compared with age- and sex-matched healthy controls. Furthermore, we wanted to evaluate the possible relationship between markers of thyroid autoimmune disease.

\section{Material and methods}

\section{Subjects}

All patients with IDDM, less than 18 years old by the first of March 1997 and living in the county of Funen 
(470000 inhabitants), Denmark, were invited to participate in the study. A total of 116 patients were identified and $105(90.5 \%)$ accepted to participate. The patients, 50 girls and 55 boys, had a median age of 12.8 years (range 2.3-18.2) and a median duration of diabetes of 4.8 years (range $0.2-13.3$ ). Two patients, a 17-year-old boy and a 16-year-old girl, were treated with levothyroxine due to previously diagnosed autoimmune thyroiditis and hypothyroidism. Three were treated with budesonide inhalation $(\leq 800 \mu \mathrm{g} /$ day $)$ because of asthma, two were treated with anti-epileptics (lamotrigin), one received angiotensin converting enzyme inhibitor due to microalbuminuria, and two girls were on oral contraceptives.

The control group comprised 105 healthy children and adolescents ( 50 girls, 55 boys) primarily relatives of the hospital staff. They were also living in the county of Funen and were matched to the diabetic children according to sex and age with a median age of 12.9 years (range 1.3-18.3). None of the controls was studied in the state of acute or recent illness. None was receiving any medication influencing thyroid function or size apart from two girls having oral contraceptives.

All diabetics and controls underwent a physical examination and a US of the thyroid gland with determination of thyroid volume and morphology. Venous blood samples were taken for determination of thyroid function variables, TPOab, Tgab and glycosylated haemoglobin $\left(\mathrm{HbA}_{1 \mathrm{c}}\right)$. $\mathrm{HbA}_{1 \mathrm{c}}$ was analysed on venous blood, otherwise serum was frozen at $-20^{\circ} \mathrm{C}$ until analysis.

All patients, controls and their parents gave informed consent, and the study was approved by the local ethical committee (case number 96/250). The study was performed in accordance with the Helsinki Declaration.

\section{Thyroid US}

The thyroid volume was calculated on the basis of a US scanning procedure using a $5.5 \mathrm{MHz}$ compound scanner (Type 1846, Brüel \& Kjær, Naerum, Denmark) as described previously (11). Two of the authors (F N B and $\mathrm{LH})$ performed all the US investigations without knowledge of to which group the subjects belonged (IDDM or control). Intraobserver variation using this accurate cross-sectional method, i.e. coefficient of variation on double determinations, has been assessed previously (19) and was $6.6 \%(\mathrm{FNB})$ and $5.1 \%(\mathrm{LH})$, and the interobserver variation was $5.0 \%$. The echo pattern was investigated with a real-time $7 \mathrm{MHz}$ linear array transducer (Type 8534, Brüel \& Kjær), dynamically focused with a focus extension of $5-50 \mathrm{~mm}$ (axial resolution $0.4 \mathrm{~mm}$ ). The gain was adjusted to produce an echo-free appearance of the lumen of the internal jugular veins, carotid arteries and neck-strap muscles. In this setting a normal thyroid gland has a medium grey-scale homogeneous echo pattern and the level of echogenicity is higher than that of the surrounding muscles. The different morphological patterns found by US were divided into five groups (Morphology Group (MG) 0-4): MG 0: normal thyroid gland, MG 1: mild to moderate diffuse hypoechogenicity, MG 2: marked, diffuse hypoechogenicity, MG 3: non-homogeneous hypoechogenicity and MG 4: uni- or multinodularity (nodules $\geq 1 \mathrm{~cm}$ ).

\section{Biochemical measurements}

Serum thyroxine $\left(\mathrm{T}_{4}\right)$ (normal range 65-135 nmol/l) was determined by RIA (Diagnostic Products Corp., Los Angeles, CA, USA) and serum tri-iodothyronine $\left(\mathrm{T}_{3}\right)$ (normal range $1.00-2.10 \mathrm{nmol} / \mathrm{l}$ ) analysed by RIA (Johnson \& Johnson, Clinical Diagnostics Ltd, Amersham, Bucks, UK). Free $\mathrm{T}_{4}$ index $\left(\mathrm{FT}_{4} \mathrm{I}\right)$ (normal range 58-137 arbitrary units/l) and free $\mathrm{T}_{3}$ index $\left(\mathrm{FT}_{3} \mathrm{I}\right)$ (normal range 0.95-2.20 arbitrary units/l) were calculated by multiplying the $\mathrm{T}_{4}$ and $\mathrm{T}_{3}$ levels respectively with the $\mathrm{T}_{3}$ uptake test. Serum thyrotrophin (TSH) (normal range 0.30-4.0 mU/l) was determined by DELFIA (Wallac OY, Turku, Finland). Serum TPOab (normal range $<60 \mathrm{U} / \mathrm{ml}$ ) and serum Tgab (normal range $<60 \mathrm{U} / \mathrm{ml}$ ) were determined by RIA (Brahms Diagnostica $\mathrm{GmbH}$, Berlin, Germany). $\mathrm{HbA}_{1 \mathrm{c}}$ (normal range $4.3-6.3 \%$ ) was determined by ion-exchange chromatography.

\section{Statistical analysis}

The results are presented as medians and ranges, and comparisons between groups were analysed by MannWhitney's unpaired rank sum test. The relationship between thyroid volume (which had an approximately normal distribution) and other variables was studied by univariate linear regression analysis followed by multiple linear regression analysis of the significant predictors. Comparisons of frequencies of Tab and US abnormalities in diabetics and controls were performed by a chi-squared test. $P$ values less than 0.05 were considered significant.

\section{Results}

\section{Clinical characteristics and biochemical measurements}

No significant differences between the groups in age, height, weight and body mass index (BMI) were found (Table 1). Only one patient in the study population, a 17-year-old diabetic girl, had a small goitre. Three diabetic girls aged 7,13 and 16 years were subclinically hypothyroid, i.e. had slightly elevated TSH (4.52, 6.18 and $4.71 \mathrm{mU} / \mathrm{l}$ respectively), but normal $\mathrm{FT}_{4} \mathrm{I}$. All other diabetics and controls were clinically and chemically euthyroid. No significant differences between diabetics and controls could be demonstrated in serum thyroid hormones and TSH values (Table 1). Among the 
Table 1 Clinical characteristics, biochemical measurements and thyroid volume in diabetics and controls. Results are presented as median (range).

\begin{tabular}{|c|c|c|c|}
\hline & $\begin{array}{l}\text { Diabetics } \\
(n=105)\end{array}$ & $\begin{array}{l}\text { Controls } \\
(n=105)\end{array}$ & Mann-Whitney $P$ value \\
\hline Age (years) & $12.8(2.3-18.2)$ & $12.9(1.3-18.3)$ & 0.974 \\
\hline Height $(\mathrm{cm})$ & $155(85-193)$ & $156(76-194)$ & 0.514 \\
\hline Weight (kg) & $47(11-86)$ & $47(10-83)$ & 0.648 \\
\hline $\operatorname{BMI}\left(\mathrm{kg} / \mathrm{m}^{2}\right)$ & $19.2(14.5-29.8)$ & $18.5(14.0-25.6)$ & 0.063 \\
\hline Duration of IDDM (years) & $4.8(0.2-13.3)$ & - & - \\
\hline Insulin (IU/kg per day) & $0.9(0.2-1.8)$ & - & - \\
\hline $\mathrm{HbA}_{1 \mathrm{c}}(\%)$ & $8.0(5.6-15.1)$ & $5.1(4.4-5.6)^{\star}$ & $<0.001$ \\
\hline $\mathrm{TSH}(\mathrm{U} / \mathrm{I})$ & $1.51(0.59-6.18)$ & $1.48(0.47-3.46)$ & 0.353 \\
\hline $\mathrm{T}_{4}(\mathrm{nmol} / \mathrm{l})$ & $94(66-189)$ & $92(54-140)$ & 0.467 \\
\hline $\mathrm{T}_{3}(\mathrm{nmol} / \mathrm{l})$ & $1.97(0.96-3.14)$ & $2.00(1.15-2.86)$ & 0.421 \\
\hline $\mathrm{FT}_{4} \mathrm{I}$ (arbitrary units/l) & $86(61-130)$ & $86(55-121)$ & 0.965 \\
\hline $\mathrm{FT}_{3} \mathrm{I}$ (arbitrary units/l) & $1.80(0.96-2.77)$ & $1.83(1.08-2.89)$ & 0.244 \\
\hline Thyroid volume (ml) & $8.7(1.5-23.2)$ & $8.6(1.3-18.3)$ & 0.421 \\
\hline
\end{tabular}

${ }^{*} n=103$.

diabetics, 17 patients (16.2\%) had Tab (13 TPOab, 14 Tgab and 10 both $), 11$ girls and 6 boys $(P=0.123)$. Clinical characteristics and the level of Tab are presented in Table 2. Only one of the two patients with previously known autoimmune thyroid disease had elevated Tab (case number 15). Of the three girls with elevated TSH only two had Tab, one of them in high concentrations (Table 2). The girl with goitre had no autoantibodies. There were no significant differences between diabetics with and without autoantibodies in age, duration of diabetes, $\mathrm{HbA}_{1 \mathrm{c}}$. TSH or thyroid hormones. In the control group only two $(1.9 \%)$ had Tab, significantly different from the diabetics $(P<0.001)$.

\section{Thyroid volume}

US revealed a median thyroid volume of $8.7 \mathrm{ml}$ (range 1.5-23.2) in the diabetic group compared with $8.6 \mathrm{ml}$ (range 1.3-18.3) in the control group $(P=0.421)$ (Table 1). Neither was there any difference in thyroid volume between diabetics and controls when comparing females $(P=0.376)$ and males $(P=0.806)$ separately. In both diabetics and controls thyroid volume correlated significantly with several variables (age, weight, height, duration of IDDM and serum $\mathrm{T}_{3}$ ). However, following multiple regression analysis, thyroid volume was in both groups only significantly correlated with age and

Table 2 Clinical characteristics of children with elevated thyroid antibodies.

\begin{tabular}{|c|c|c|c|c|c|c|c|c|}
\hline Patients & $\begin{array}{c}\text { Sex } \\
(F / M)\end{array}$ & $\begin{array}{c}\text { Age } \\
\text { (years) }\end{array}$ & $\begin{array}{c}\text { Duration } \\
\text { of IDDM } \\
\text { (years) }\end{array}$ & $\begin{array}{l}\text { TPOab } \\
\text { (IU/ml) }\end{array}$ & $\begin{array}{c}\text { Tgab } \\
\text { (IU/ml) }\end{array}$ & $\begin{array}{l}\text { Thyroid } \\
\text { volume } \\
\text { (ml) }\end{array}$ & $\begin{array}{c}\text { Morphology } \\
\text { group } \\
\text { (MG 0-4) }\end{array}$ & $\begin{array}{c}\text { TSH } \\
(\mathrm{mU} / \mathrm{l})\end{array}$ \\
\hline 1 & $\mathrm{~F}$ & 2 & 1 & 385 & Negative & 2.3 & 1 & 3.00 \\
\hline 2 & $\mathrm{~F}$ & 4 & 3 & 89 & 77 & 2.9 & 0 & 3.27 \\
\hline 3 & $M$ & 4 & 2 & Negative & 67 & 3.4 & 0 & 1.43 \\
\hline 4 & $\mathrm{~F}$ & 7 & 6 & 194 & $>2000$ & 5.5 & 1 & 4.52 \\
\hline 5 & $M$ & 9 & 6 & 79 & Negative & 8.6 & 1 & 1.32 \\
\hline 6 & $\mathrm{~F}$ & 9 & 1 & Negative & 65 & 9.9 & 0 & 2.34 \\
\hline 7 & $\mathrm{~F}$ & 11 & 8 & Negative & 78 & 9.0 & 0 & 1.96 \\
\hline 8 & $\mathrm{~F}$ & 12 & 0.25 & 107 & 184 & 14.4 & 0 & 1.27 \\
\hline 9 & $M$ & 13 & 4 & 210 & 538 & 12.3 & 1 & 1.21 \\
\hline 10 & $\mathrm{~F}$ & 13 & 2 & Negative & 290 & 12.7 & 1 & 6.18 \\
\hline 11 & $M$ & 14 & 8 & 1845 & 102 & 10.0 & 1 & 1.70 \\
\hline 12 & $\mathrm{~F}$ & 14 & 10 & 807 & 64 & 13.0 & 3 & 1.04 \\
\hline 13 & $\mathrm{~F}$ & 16 & 9 & $>3000$ & 133 & 17.4 & 2 & 1.93 \\
\hline 14 & $M$ & 17 & 1 & 857 & 71 & 20.6 & 0 & 1.33 \\
\hline $15^{\star}$ & $M$ & 17 & 8 & $>3000$ & $>2000$ & 15.4 & 1 & 3.72 \\
\hline 16 & $\mathrm{~F}$ & 17 & 2 & 329 & Negative & 10.4 & 1 & 1.34 \\
\hline 17 & $\mathrm{~F}$ & 17 & 7 & 677 & 152 & 21.1 & 0 & 0.83 \\
\hline $18^{\star *}$ & $\mathrm{~F}$ & 11 & - & 79 & 63 & 11.9 & 0 & 2.25 \\
\hline $19^{* *}$ & $M$ & 17 & - & 972 & 0 & 12.3 & 3 & 1.68 \\
\hline
\end{tabular}

* Previously diagnosed autoimmune thyroid disease.

${ }^{* *}$ Controls. 
weight. The relationship between thyroid volume and age and weight is demonstrated in Fig. 1.

\section{Thyroid morphology}

The distribution of the different MGs in diabetics and controls is presented in Table 3. Morphological abnormalities (MG 1-4) were found in $42 \%$ of the diabetics compared with $11 \%$ in the control group $(P<0.001)$. In the diabetic group $50 \%$ of the girls and $35 \%$ of the boys had some kind of morphological abnormality $(P=0.109)$. In the control group, $8 \%$ of the girls and $13 \%$ of the boys $(P=0.430)$ had such abnormalities. The two patients with previously diagnosed autoimmune thyroiditis demonstrated non-homogeneous hypoechogenicity and moderate diffuse hypoechogenicity respectively. Of the three patients with subclinical hypothyroidism, those two with Tab also had moderate, diffuse hypoechogenicity, while the third had a normal US. In the girl with goitre, US demonstrated multinodularity; her mother also had a non-toxic multinodular goitre. The most frequent morphological abnormalities in the diabetic patients were mild to moderate diffuse hypoechogenicity $(23.8 \%$ of the patients) and non-homogeneous hypoechogenicity (12.4\% of the patients). The abnormalities found in the control group comprised all the different morphological types. Table 3 also shows the distribution of age,

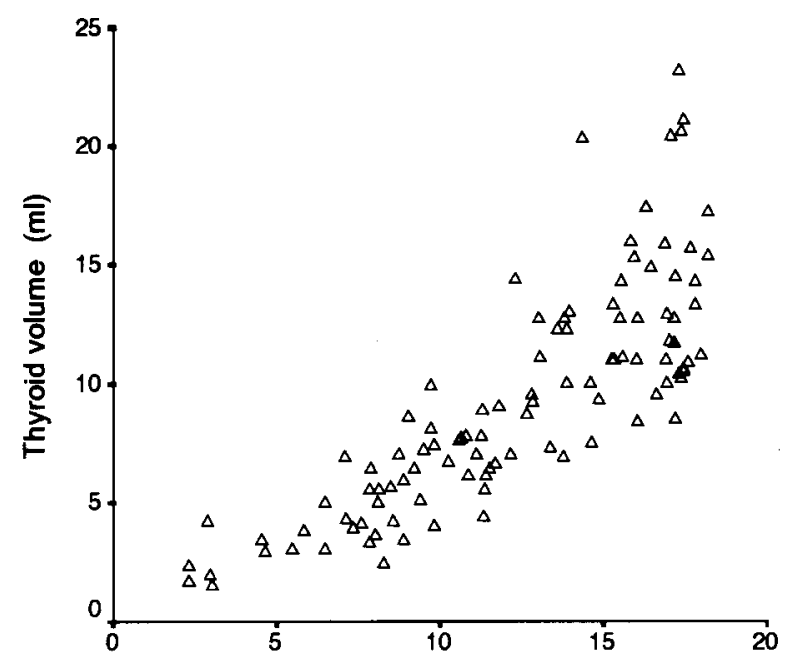

Age (yr)

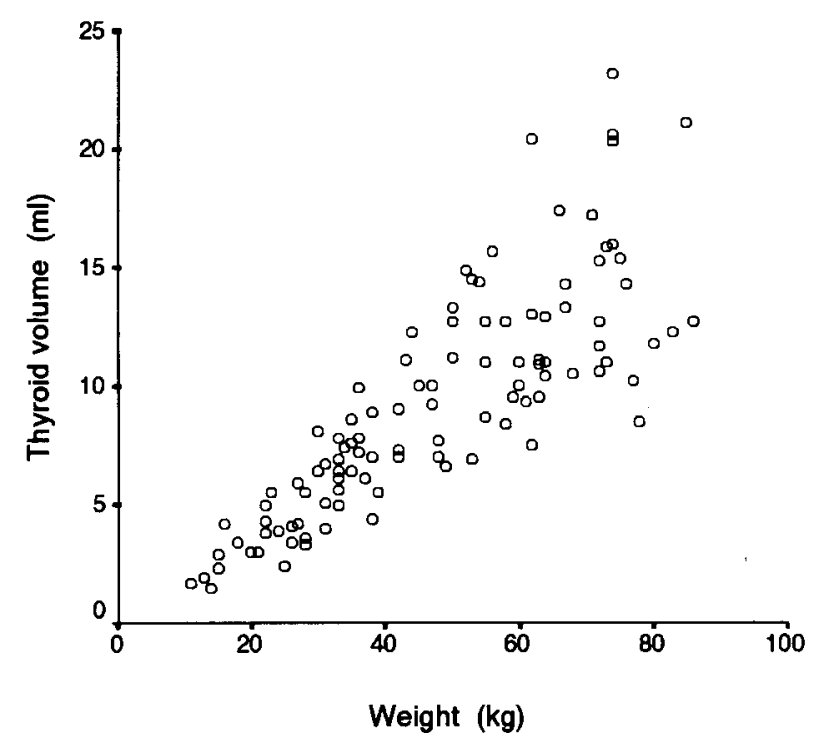

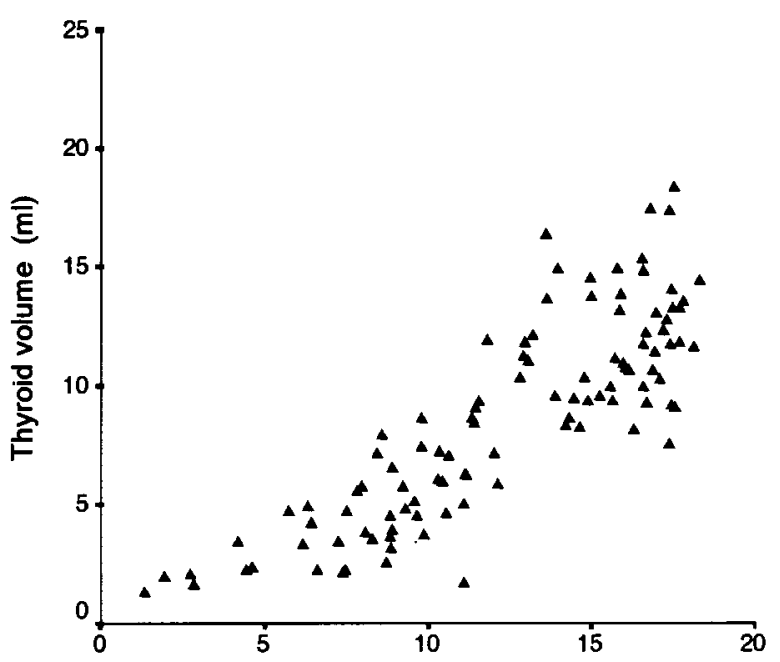

Age (yr)

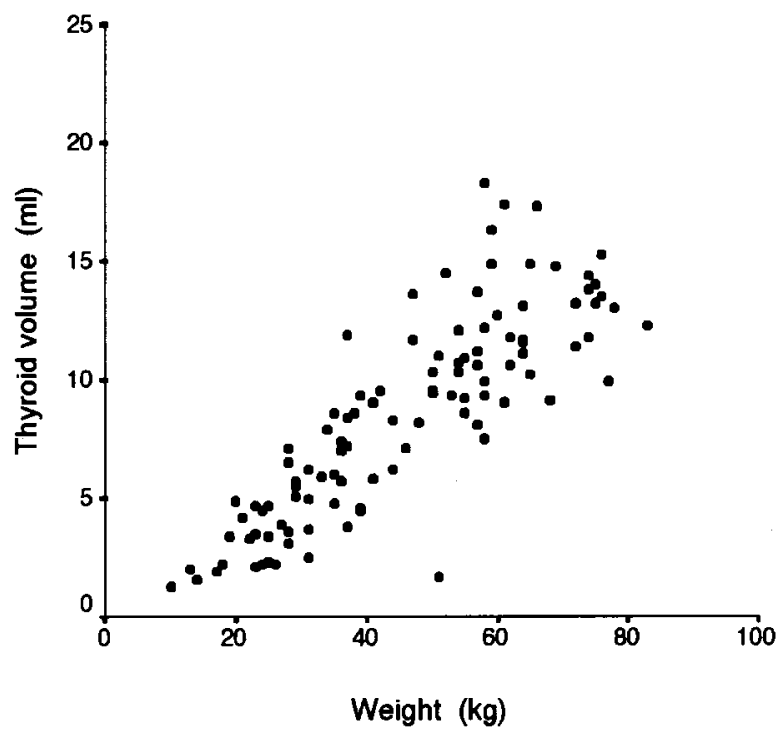

Figure 1 Thyroid volume related to age (upper panels) for (left) diabetics $(\triangle)$ and (right) controls $(\mathbf{\Lambda})$ and to weight (lower panels) for (left) diabetics $(O)$ and right controls $(\bullet)$. 
Table 3 The distribution of diabetics and controls in the different MGs and for the diabetics the relation to age, duration of diabetes, $\mathrm{HbA}_{1 \mathrm{c}}$, $\mathrm{TSH}$ and thyroid volume (median and range).

\begin{tabular}{|c|c|c|c|c|c|c|c|}
\hline \multirow[b]{2}{*}{$\begin{array}{l}\text { Morphology } \\
\text { group* } \\
\text { (MG 0-4) }\end{array}$} & \multirow[b]{2}{*}{$\begin{array}{c}\text { Controls } \\
(n(\%))\end{array}$} & \multirow[b]{2}{*}{$\begin{array}{c}\text { Diabetics } \\
(n(\%))\end{array}$} & \multicolumn{5}{|c|}{ Diabetics } \\
\hline & & & $\begin{array}{c}\text { Age } \\
\text { (years) }\end{array}$ & $\begin{array}{l}\text { Duration of } \\
\text { IDDM } \\
\text { (years) }\end{array}$ & $\begin{array}{c}\mathrm{HbA}_{1 \mathrm{c}} \\
(\%)\end{array}$ & $\begin{array}{l}\text { TSH } \\
(\mathrm{U} / \mathrm{l})\end{array}$ & $\begin{array}{l}\text { Thyroid } \\
\text { volume } \\
\text { (ml) }\end{array}$ \\
\hline 0 & 94 (89) & $61(58)$ & $11.4(2.3-18.0)$ & $3.9(0.2-12.2)$ & $8.0(5.6-11.5)$ & $1.41(0.59-4.71)$ & $7.8(1.7-21.1)$ \\
\hline 1 & $4(4)$ & $25(24)$ & $9.5(2.4-18.2)$ & $4.8(0.4-8.7)$ & $7.6(6.1-11.5)$ & $1.90(0.62-6.18)$ & $6.6(1.5-15.7)$ \\
\hline 2 & $1(1)$ & $4(4)$ & $15.8(12.7-16.9)$ & $10.5(3.4-12.3)$ & $9.4(7.2-15.1)$ & $1.84(1.21-2.17)$ & $13.1(8.7-17.4)$ \\
\hline 3 & $3(3)$ & $13(12)$ & $16.0(12.8-18.2)$ & $8.1(1.0-13.3)$ & $9.3(6.5-13.4)$ & $1.51(0.86-3.19)$ & $12.7(7.3-20.3)$ \\
\hline 4 & $3(3)$ & $2(2)$ & $14.4(11.5-17.3)$ & $6.9(3.3-10.4)$ & $7.9(6.7-9.00)$ & $0.85(0.78-0.92)$ & $14.8(6.4-23.2)$ \\
\hline
\end{tabular}

* MG 0: normal thyroid gland; MG 1: mild to moderate diffuse hypoechogenicity; MG 2: marked, diffuse hypoechogenicity; MG 3: nonhomogeneous hypoechogenicity; MG 4: uni- or multinodularity.

duration of diabetes, $\mathrm{HbA}_{1 \mathrm{c}}$, TSH and thyroid volume in relation to the morphological findings in diabetics. When comparing diabetic patients with a normal US (MG O) with those having mild to moderate diffuse hypoechogenicity (MG 1) no significant differences in age, duration of diabetes, $\mathrm{HbA}_{1 \mathrm{c}}$ or thyroid volume were found, but serum TSH was significantly higher in MG 1 $(P=0.006)$. When comparing diabetics in MG 0 with those with non-homogeneous hypoechogenicity (MG 3) there was a significantly higher age $(P=0.012)$, duration of diabetes $(P=0.003), \mathrm{HbA}_{1 \mathrm{c}}(P=0.001)$ and thyroid volume $(P=0.002)$ in MG 3 , while serum TSH was almost the same in the two groups. Because of the low number of children in MG 1-4 similar comparisons between MGs were not made for the controls.

Of diabetics with any kind of US abnormality, 10 (23\%) had Tab whereas 34 (77\%) had no antibodies. Conversely, in diabetics without US abnormalities 7 (11\%) had Tab and 54 (89\%) had no antibodies, the concurrent occurrence of US abnormalities and Tab being non-significant $(P=0.123)$.

\section{Discussion}

In this study thyroid dysfunction was present in five subjects $(4.8 \%)$. Two patients were already receiving treatment for hypothyroidism and three patients were diagnosed for the first time with subclinical hypothyroidism, though with marginally elevated TSH. This prevalence of thyroid dysfunction is in agreement with previous studies of young diabetics $(3,5)$ but lower than that found in an extensive study of adult patients with IDDM demonstrating $13.4 \%$ to have clinical or subclinical thyroid dysfunction (20).

The study confirms that young diabetics have a higher prevalence of Tab (16\%) than healthy controls $(1.9 \%)$. Similar prevalences were found in several other studies in young $(3,5,6)$ and in adult diabetics $(1,2)$. In contrast a recent study of newly diagnosed young diabetics showed a considerably higher prevalence with $44 \%$ having either Tgab or TPOab (7). Possible explanations for this difference could be ethnic variations, difference in iodine intake, a more sensitive assay in the latter study or alternatively immunological abnormalities present at diagnosis of IDDM before the start of insulin treatment. In accordance with Lindberg et al. (7) we found antibody-positive patients in all age groups, which is in contrast to Lorini et al. (21), who only found Tab in children older than 10 years. In our antibody-positive patients the duration of diabetes varied between 0.25 and 10 years. Another study found a higher prevalence in patients with duration of diabetes more than 10 years, but also found an overall higher prevalence of $30 \%$ (22). Previous studies reported that Tab are more frequent among girls than boys $(1,21,22)$, while we and others $(3,7)$ did not find such a difference.

It has been questioned whether Tgab provides further diagnostic information compared with the single use of TPOab (or Micab) in the diagnosis of autoimmune thyroid disease $(1,8,23)$. In our study Tab were with equal frequency directed against Tg and TPO with 14 of 17 of antibody-positive patients having Tgab and 13 of 17 having TPOab. Additionally, 4 of 17 had only Tgab indicating that information is missed if only TPOab are measured.

It is difficult to compare our thyroid volume results with previous studies due to differences in age distribution and iodine intake. Our results seem in agreement with an extensive study of healthy children from 12 European countries (13) and with a smaller study of Turkish diabetic and control children (5). On the other hand, compared with studies of Italian and Swedish children, living in iodine-sufficient areas, our children had a considerably higher thyroid volume through the different age groups $(24,25)$. The fact that the Funen population is borderline iodine deficient (daily urinary iodine excretion $50-80 \mu \mathrm{g})(26)$ is the most likely explanation for this marked difference. Minor differences in thyroid volume could also be explained by differences in the method of determining thyroid volume. In the present study thyroid volume was measured by a cross-sectional method (inaccuracy $5-10 \%)$, in the others by a method with an inaccuracy 
of $15-20 \%$. Confirming previous studies we found thyroid volume primarily to be dependent on age and weight $(5,12,13,24,25)$ and without relation to the level of thyroid hormones $(5,11,27)$. In agreement with the study by Darendeliler et al. (5) we found no difference in thyroid volume between diabetics and controls. In contrast, a study of 45 adult IDDM patients with no history of thyroid disease showed a notably higher thyroid volume in diabetics than in age- and sexmatched controls (27). This higher thyroid volume could be an expression of an ongoing autoimmune process causing alterations in the thyroid gland in many of the diabetics.

In diabetics a high prevalence of morphological abnormalities by thyroid US was demonstrated. This finding is not supported by Darendeliler et al. demonstrating US abnormalities in only 2 of 83 young diabetics (5). We have no obvious explanations for this discrepancy. Our investigations were performed by two experienced examiners who were blinded according to whether the patients were diabetics or controls. The dominant US finding in our study was various degrees of hypoechogenicity. This US abnormality has previously been described in patients with autoimmune thyroid disease where the diagnosis was additionally confirmed by either fine-needle aspiration biopsy or the presence of Tab (14). However, our study showed no obvious relationship between the occurrence of US hypoechogenicity and Tab. The prevalence of US hypoechogenicity was considerably higher than the prevalence of Tab and seven patients had Tab without concomitant US abnormalities. However, there was a tendency towards patients having higher antibody concentrations also having morphological abnormalities, and conversely some patients with low antibody concentrations had a normal US (Table 2). Also the strikingly higher frequency of US hypoechogenicity in diabetics compared with controls (40\% versus $8 \%$ ), and a significantly higher TSH in MG 1 and 2 compared with MG 0 in diabetics, points at US hypoechogenicity being a marker of autoimmune thyroid disease.

To our knowledge there are no other studies, except for the one by Darendeliler et al. (5), which have evaluated the relationship between Tab and US in diabetics. Previous studies in non-diabetics with known or suspected thyroid disease are conflicting. In patients diagnosed with autoimmune thyroid disease (by Tab and/or fine-needle aspiration biopsy) prevalences of US abnormalities of $18-95 \%$ are reported $(10,15,17)$. The US finding of hypoechogenicity is not specific for the diagnosis of autoimmune thyroid disease but is also seen, for example, in Graves' disease and subacute thyroiditis $(10,17)$. However, some studies have shown US hypoechogenicity to be a valuable prognostic marker in autoimmune thyroid disease predicting the development of hypothyroidism $(10,17)$.

Presently, we do not know the significance of our US results. One can speculate that US hypoechogenicity might be an early sign of an autoimmune process in the thyroid gland and thus a prognostic marker of future autoimmune thyroiditis. Further investigations including a regular follow-up of the patients from this study are needed.

In conclusion, we demonstrated that a large proportion of diabetic children and adolescents with a relatively short duration of diabetes have markers of thyroid autoimmune disease. A few have thyroid dysfunction, many have Tab, but even more have abnormalities by thyroid US, the significance of this needing further investigation.

\section{Acknowledgements}

This study was supported by grants from The Clinical Institute of Research, Odense University, The Agnes and Knut Mørk Foundation, The Foundation of Medical Research of the county of Funen, The Else Poulsen Foundation, The Gerda and Aage Haensch Foundation, The Dagmar Marshall Foundation and ASTRA Denmark.

\section{References}

1 Riley WJ, Maclaren NK, Lezotte DC, Spillar RP \& Rosenbloom AL. Thyroid autoimmunity in insulin-dependent diabetes mellitus: the case for routine screening. Journal of Pediatrics $198199350-$ 354.

2 Betterle C, Zanette F, Pedini B, Presotto F, Rapp LB, Monciotti CM et al. Clinical and subclinical organ-specific autoimmune manifestations in type 1 (insulin-dependent) diabetic patients and their first-degree relatives. Diabetologia 198426 431-436.

3 McKenna MJ, Herskowitz R \& Wolfsdorf JI. Screening for thyroid disease in children with IDDM. Diabetes Care 199013 801803 .

4 Kontiainen S, Schlenzka A, Koskimies S, Rilva A \& Maenpaa J. Autoantibodies and autoimmune diseases in young diabetics. Diabetes Research 199013 151-156.

5 Darendeliler FF, Kadioglu A, Firdevs B, Bundak R, Günöz H, Saka $\mathrm{N}$ et al. Thyroid ultrasound in IDDM. Journal of Pediatric Endocrinology 19947 33-37.

6 Lorini R, d'Annunzio G, Vitali L \& Scaramuzza A. IDDM and autoimmune thyroid disease in the pediatric age group. Journal of Pediatric Endocrinology and Metabolism 1996 9 89-94.

7 Lindberg B, Ericsson UB, Ljung R \& Ivarsson SA. High prevalence of thyroid autoantibodies at diagnosis of insulin-dependent diabetes mellitus in Swedish children. Journal of Laboratory and Clinical Medicine 1997130 585-589.

8 Feldt Rasmussen U, Hoier Madsen M, Bech K, Blichert Toft M, Bliddal H, Date J et al. Anti-thyroid peroxidase antibodies in thyroid disorders and non-thyroid autoimmune diseases. Autoimmunity 19919 245-254.

9 Mariotti S, Caturegli P, Piccolo P, Barbesino G \& Pinchera A. Antithyroid peroxidase autoantibodies in thyroid diseases. Journal of Clinical Endocrinology and Metabolism $199071661-669$.

10 Sostre S \& Reyes MM. Sonographic diagnosis and grading of Hashimoto's thyroiditis. Journal of Endocrinological Investigation $199114115-121$.

11 Hegedüs L, Perrild H, Poulsen LR, Andersen JR, Holm B, Schnohr $\mathrm{P}$ et al. The determination of thyroid volume by ultrasound and its relationship to body weight, age, and sex in normal subjects. Journal of Clinical Endocrinology and Metabolism 198356 260263.

12 Ueda D. Normal volume of the thyroid gland in children. Journal of Clinical Ultrasound 199718 455-462. 
13 Delange F, Benker G, Caron P, Eber O, Ott W, Peter F et al. Thyroid volume and urinary iodine in European schoolchildren: standardization of values for assessment of iodine deficiency. European Journal of Endocrinology 1997136 180-187.

14 Ivarsson SA, Ericsson UB, Fredriksson B \& Persson PH. Ultrasonic imaging in the differential diagnosis of diffuse thyroid disorders in children. American Journal of Diseases of Children 19891431369 1372 .

15 Gutekunst R, Hafermann W, Mansky T \& Scriba PC. Ultrasonography related to clinical and laboratory findings in lymphocytic thyroiditis. Acta Endocrinologica 1989121 129-135.

16 Nordmeyer JP, Shafeh TA \& Heckmann C. Thyroid sonography in autoimmune thyroiditis. A prospective study on 123 patients. Acta Endocrinologica 1990122 391-395.

17 Marcocci C, Vitti P, Cetani F, Catalano F, Concetti R \& Pinchera A. Thyroid ultrasonography helps to identify patients with diffuse lymphocytic thyroiditis who are prone to develop hypothyroidism. Journal of Clinical Endocrinology and Metabolism 199172 209213.

18 Radetti G, Paganini C, Gentili L, Bernasconi S, Betterle C, Borkenstein M et al. Frequency of Hashimoto's thyroiditis in children with type 1 diabetes mellitus. Acta Diabetologica 199532 121-124.

19 Hegedüs L, Karstrup S \& Rasmussen N. Evidence of cyclic alterations of thyroid size during the menstrual cycle in healthy women. American Journal of Obstetrics and Gynecology 1986155 142-145.

20 Perros P, McCrimmon RJ, Shaw G \& Frier BM. Frequency of thyroid dysfunction in diabetic patients: Value of annual screening. Diabetic Medicine 199512 622-627.
21 Lorini R, Larizza D, Livieri C, Cammareri V, Martini A, Plebani A et al. Auto-immunity in children with diabetes mellitus and in their relatives. European Journal of Pediatrics 1986145 182-184. 22 Bright GM, Blizzard RM, Kaiser DL \& Clarke WL. Organ-specific autoantibodies in children with common endocrine diseases. Journal of Pediatrics 1982100 8-14.

23 Doullay F, Ruf J, Carayon P \& Codaccioni JL. Autoantibodies to thyroperoxidase in various thyroid and autoimmune diseases. In Thyroperoxidase and Thyroid Autoimmunity, pp 285-295. Eds P Carayon \& J Ruf. London: John Libbey Eurotext Ltd, 1990.

24 Ivarsson SA, Persson PH \& Ericsson UB. Thyroid gland volume as measured by ultrasonography in healthy children and adolescents in a non-iodine deficient area. Acta Paediatrica Scandinavica $198978633-634$.

25 Vitti P, Martino E, Aghini-Lombardi F, Rago T, Antonangeli L, Baslestrieri A et al. Thyroid volume measurement by ultrasound in children as a tool for the assessment of mild iodine deficiency. Journal of Clinical Endocrinology and Metabolism 199479 600-603.

26 Haas V, Mariey M, Green A, Date J, Blichert Toft M \& Mogensen EF. Urinary iodine excretion in a geographically stratified Danish population sample not affected by iodination programmes. A change towards higher values. Acta Endocrinologica 1988119 125131.

27 Bianchi G, Montanari P, Fabbri A, Gamberini A, Zoli M \& Marchesini G. Thyroid volume in type 1 diabetes patients without overt thyroid disease. Acta Diabetologica 199532 49-52.

Received 11 November 1998

Accepted 9 February 1999 